\title{
Long-term trends of black carbon and particle number concentration in the lower free troposphere in Central Europe
}

Jia Sun', Markus Hermann', Ye Yuan², Wolfram Birmili'1,3, Martine Collaud Coen ${ }^{4}$, Kay Weinhold', Leizel Madueño ${ }^{1}$, Laurent Poulain' ${ }^{1}$,Thomas Tuch ${ }^{1}$, Ludwig Ries ${ }^{5}$, Ralf Sohmer ${ }^{5}$, Cedric Couret ${ }^{5}$, Gabriele Frank ${ }^{6}$,

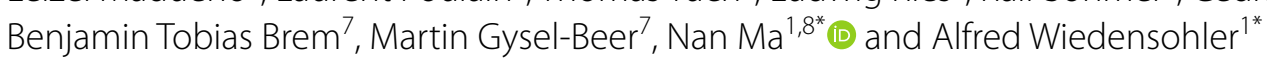

\begin{abstract}
Background: The implementation of emission mitigation policies in Europe over the last two decades has generally improved the air quality, which resulted in lower aerosol particle mass, particle number, and black carbon mass concentration. However, little is known whether the decreasing particle concentrations at a lower-altitude level can be observed in the free troposphere (FT), an important layer of the atmosphere, where aerosol particles have a longer lifetime and may affect climate dynamics. In this study, we used data from two high-Alpine observatories, ZugspitzeSchneefernerhaus (ZSF) and Jungfraujoch (JFJ), to assess the long-term trends on size-resolved particle number concentrations (PNCs) and equivalent black carbon (eBC) mass concentration separated for undisturbed lower FT conditions and under the influence of air from the planetary boundary layer (PBL) from 2009 to 2018.

Results: The FT and PBL-influenced conditions were segregated for both sites. We found that the FT conditions in cold months were more prevalent than in warm months, while the measured aerosol parameters showed different seasonal patterns for the FT and PBL-influenced conditions. The pollutants in the PBL-influenced condition have a higher chance to be transported to high-altitudes due to the mountainous topography, leading to a higher concentration and more distinct seasonal variation, and vice versa. The long-term trends of the measured aerosol parameters were evaluated and the decreased aerosol concentrations were observed for both FT and PBL-influenced conditions. The observed decreasing trends in eBC concentration in the PBL-influenced condition are well consistent with the reported trends in total BC emission in Germany and Switzerland. The decreased concentrations in the FT condition suggest that the background aerosol concentration in the lower FT over Central Europe has correspondingly decreased. The change of back trajectories in the FT condition at ZSF and JFJ was further evaluated to investigate the other possible drivers for the decreasing trends.
\end{abstract}

Conclusions: The background aerosol concentration in the lower FT over Central Europe has significantly decreased during 2009-2018. The implementation of emission mitigation policies is the most decisive factor and the decrease of the regional airmass occurrence over Central Europe also has contributed to the decreasing trends.

Keywords: Black carbon, Particle number concentration, Long-term trend, Free troposphere

*Correspondence: nan.ma@jnu.edu.cn; ali@tropos.de

${ }^{1}$ Leibniz Institute for Tropospheric Research (TROPOS), Leipzig, Germany

${ }^{8}$ Institute for Environmental and Climate Research, Jinan University,

Guangzhou, China

Full list of author information is available at the end of the article

\section{Background}

Atmospheric sub-micrometer aerosol particles (diameter $<1 \mu \mathrm{m}$ ) can affect the global radiation budget through scattering and absorbing solar radiation [1]. These particles can also act as cloud condensation nuclei and ice

\section{Springer Open}

(c) The Author(s) 2021. This article is licensed under a Creative Commons Attribution 4.0 International License, which permits use, sharing, adaptation, distribution and reproduction in any medium or format, as long as you give appropriate credit to the original author(s) and the source, provide a link to the Creative Commons licence, and indicate if changes were made. The images or other third party material in this article are included in the article's Creative Commons licence, unless indicated otherwise in a credit line to the material. If material is not included in the article's Creative Commons licence and your intended use is not permitted by statutory regulation or exceeds the permitted use, you will need to obtain permission directly from the copyright holder. To view a copy of this licence, visit http://creativeco mmons.org/licenses/by/4.0\%. 
nuclei to modify cloud properties and precipitation [2, 3]. Black carbon (BC) is one of the essential components of aerosol particles. Due to its strong absorption of solar radiation, $\mathrm{BC}$ warms the atmosphere [4]. In terms of climatic impacts, aerosol particles are more important in the free troposphere (FT) than in the planet boundary layer ( $\mathrm{PBL}$ ), since $\mathrm{BC}$ above clouds have much higher direct radiative efficiency than $\mathrm{BC}$ close to the surface [5-7]. Besides, aerosol particles participate in the formation of clouds by acting as condensation nuclei, which depends on their size and composition [8]. This leads to in- or semi-direct effects of aerosols on climate $[9,10]$. Thus, aerosol particles in the FT also have important research significance. Moreover, aerosol particles have a longer transport distance due to their longer lifetime in the FT. The aerosol measurements in the FT can represent the background aerosol concentration over a large spatial scale $[11,12]$.

The aerosol particles in the FT are mainly transported from the PBL. Direct emission into the FT, e.g., from aviation, accounts for only a small part. The pollutants emitted in the PBL are more readily transported into the FT over a mountainous area than over flat terrain. There are passive and active effects in mountainous areas to transport the pollutants in the PBL upwards [13]. Passive effect means the airflow modified due to mountain terrains, such as orographic lifting and lee wave. Active effect modifies the airflow more often, especially under dry and convective weather in daytime, includes thermal and radiative exchange resulting from mountain terrain, diurnal heating and cooling cycles, such as the thermally driven wind system caused by the difference in horizontal air temperature and air pressure in slope, valley, and basin area. Henne et al. [14] simulated how the airflow in the PBL enters FT through topographic venting in the Alpine area. Under fair weather, the valley acts as an "air pump" in the mountainous area. During the day, the airmass in the valley will move upward, and aerosol particles in the air will also be transported upward. Then a layer named "PBL injection layer" or "aerosol layer" will be formed. Aerosols in the PBL injection layer can be further transported into the lower FT, and thereafter can be driven over large distances by synoptic flow in the FT. This mechanism enables the transport of the emitted aerosols from the PBL to the FT, which further affects the background aerosol concentration in the FT over a large special scale. In general, PBL injections are more frequent in spring and summer. During summer nights, the concentration of aerosol remaining in the FT is also higher than in other seasons due to the influence of the residual layer and PBL injection layer [15], leading to a certain seasonal variability in aerosol concentration in the FT.
Inside the PBL, the total emissions of many primary pollutants and precursor gases have decreased since 2000 due to the implementation of emission mitigation policies in Europe [16]. This may have led to fewer pollutants transported from the PBL to the FT in the mountainous area. Therefore, measurements of aerosol particles in high-altitudes can provide an opportunity to evaluate whether the emission mitigation policies at a lower-altitude level can affect the background aerosol concentration in the FT over a larger spatial scale. Several long-term studies have been conducted to investigate the trends of aerosol concentrations in Europe [17-29], these studies are not an exhaustive compilation of long-term trend analysis]. However, most of them were conducted at a lower elevation. These observations represent PBL conditions and maybe sometimes influenced by the nearground emissions, and cannot well represent the air in FT over a very large spatial scale $(\sim 100-1000 \mathrm{~km})$.

Representing background conditions in the FT over Central Europe, measurements of particle number concentration (PNC) and equivalent $\mathrm{BC}(\mathrm{eBC})$ mass concentration have been measured since the 1990s in the high-Alpine region in Central Europe. According to the long-term study by Asmi et al. [21], no statistically significant increase or decrease can be observed in the total $\mathrm{PNC}$ and $\mathrm{eBC}$ mass at the high-Alpine site Jungfraujoch (JFJ) for the period 1997-2010. In this observation period (1997-2010), the trend in total PNC was also evaluated for two overlapping periods: 1997-2005 [30] and 2001-2010 [21]. The total PNC significantly increased during the first sub-time-period, and then significantly decreased (about $-2 \%$ per year) for the second sub-timeperiod. Some trend analyses evaluated the long-term change in $\mathrm{PNC}$ and $\mathrm{eBC}$ mass at the high-Alpine stations for the period 2009-2018. The decreasing trend in eBC mass concentration was detected during this observation period at site Zugspitze-Schneefernerhaus (ZSF) [20, 22], while no trend was observed at JFJ [23]. For PNC, significant decreases were observed at both JFJ and ZSF, during 2009-2018 [20]. The detected decreases are resulted from the reduced emissions by the implementation of the emission mitigation policies over Europe.

Due to its location, observations in high-altitudes can be subdivided into two conditions: (1) undisturbed lower FT, and (2) influenced by PBL. The long-term measurements at JFJ and ZSF make it possible to determine aerosol concentration trends segregated by the FT and PBL conditions. Previous trend analyses, however, were all evaluated over the entire dataset, combining lower FT and PBL conditions. The influence of the lower FT or PBL air was only discussed based on basic splitting of the dataset, e.g., by assessing trends separately for each calendar month or daytime/night-time [30]. To the authors' 
knowledge, no study has been conducted considering the trend of PNC and BC segregated by lower FT and PBL conditions.

In this study, a long-term trend analysis of the submicrometer $\mathrm{PNC}$ and $\mathrm{BC}$ mass concentration during 2009-2018 at the two high-Alpine sites ZSF and JFJ was performed separately for both lower FT and PBL conditions. This study aims to identify if the decreased emission at the lower-altitude has affected the aerosol loading in the aged, well-mixed FT air. First, the FT and PBLinfluenced conditions were segregated by the method of adaptive diurnal minimum variation selection (ADVS), using the $\mathrm{BC}$ mass concentration as a tracer. Then, the trends in the $\mathrm{PNC}$ and $\mathrm{BC}$ mass concentration were investigated for the FT and PBL-influenced conditions. Furthermore, the airmasses arriving at the two sites during FT periods were analyzed, to investigate the possible drivers for the long-term change of background aerosol concentrations in the FT over Central Europe.

\section{Methodology}

\section{Alpine high-altitude measurement observatories}

The environmental research station Zugspitze-Schneefernerhaus (ZSF, $47.42^{\circ} \mathrm{N}, 10.98^{\circ} \mathrm{E}, 2671 \mathrm{~m}$ a.s.l.) is an observatory on the south side of Zugspitze mountain in southern Germany, whose activities focus on studying and capturing long-term changes of atmospheric pollutant concentration in the PBL and lower FT over Central Europe. ZSF is a member station of WMO's Global Atmosphere Watch (GAW) program, ACTRIS (Aerosols, Clouds and Trace gases Research InfraStructure Network), and the German Ultrafine Aerosol Network
(GUAN). As shown in Fig. 1, the ZSF observatory is located above the "Zugspitzplatt" plateau, on the southern flank of Zugspitze, the highest mountain in Germany. The upper part of the Zugspitzplatt plateau is covered by Germany's largest glacier, "Schneeferner", which descends from west to east. Owing to the climatology of synoptic airflow in Central Europe, ZSF is influenced by westerly winds most of the time [31,32].

Another high Alpine station Jungfraujoch (JFJ, 46.55 $\mathrm{N}, 7.99^{\circ} \mathrm{E}, 3580 \mathrm{~m}$ a.s.l.) is also a number of global GAW and ACTRIS station [33]. The site is located on the mountain saddle between the Jungfraujoch ( $4158 \mathrm{~m}$ a.s.l) and the Mönch (4089 m a.s.l) mountains in the Swiss Alps. Due to its high altitude and remote location, measurements on JFJ were often used to evaluate the longrange transport processes within the FT and the effects of vertical transport from the PBL to the FT in the Central Alps [15, 34-36].

\section{Instrumentation}

$\mathrm{eBC}$ mass concentrations were derived from measurements of the particle light absorption coefficient, $\sigma_{\text {abs }}$, using Multi-Angle Absorption Photometers (MAAP, model 5012, Thermo Scientific) at ZSF and JFJ. At ZSF, eBC measurements commenced in 2009 within the GUAN activity, while the corresponding measurement at JFJ started in 2003. To make the trend results of the two sites comparable, we chose the same period (2009-2018) when analyzing the eBC mass concentration. The conversion between $\sigma_{\mathrm{abs}}$ and $\mathrm{eBC}$ mass concentration was done with a mass absorption cross-section (MAC) of 6.6 $\mathrm{m}^{2} \mathrm{~g}^{-1}$ at a wavelength of $\lambda=637 \mathrm{~nm}[37,38]$. The actual
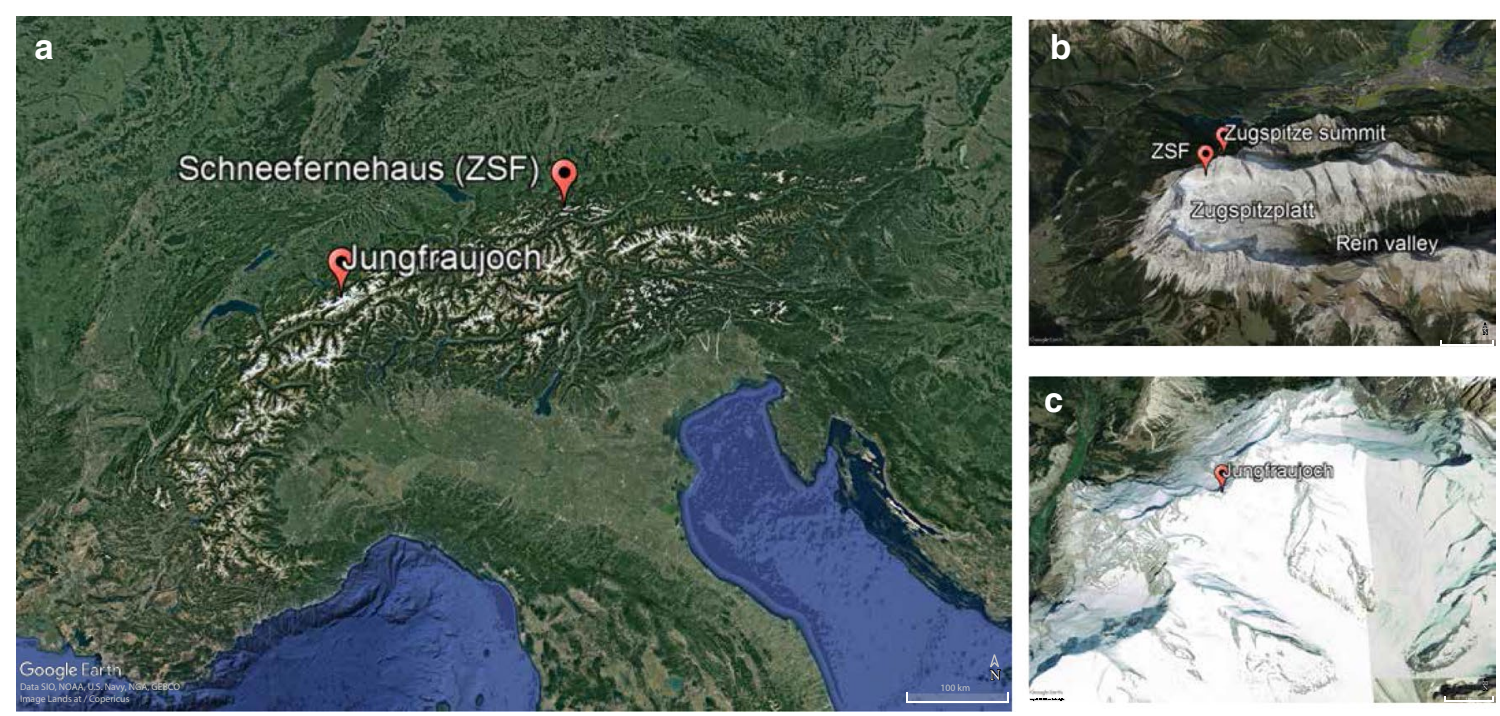

Fig. 1 Map of two observation sites ZSF and JFJ. Source: Google Earth, as of 2020/06/30 
MAC is expected to be larger than the applied value [39], however, this does not affect trend analyses as potential trends in the MAC are expected to be marginal.

A Mobility Particle Size Spectrometer (MPSS; model 3936, TSI Inc., Shoreview, USA) has been used in ZSF to measure particle number size distribution (PNSD) between the mobility diameter range $20-600 \mathrm{~nm}$ since December 2004. Detailed information about the MPSS measurement and the associated quality assurance (within the uncertainty of $\pm 10 \%$ over the entire measurement period) are provided in Birmili et al. [40].

At JFJ, a custom-built MPSS has been used to measure the PNSD for the particle mobility diameter range between 20 and $570 \mathrm{~nm}$ since 2008. The MPSS consists of a differential mobility analyzer (DMA) that has a geometry identical to the TSI model 3081 and a condensation particle counter (CPC Model 3775, TSI Inc., Shoreview, USA). Jurányi et al. [36] provided the details of the measurement setup. The MPSS instruments at both sites, JFJ and ZSF, were validated by the procedures described in Wiedensohler et al. [41]. The uncertainty between the integral MPSS-derived PNC and the PNC independently measured by a CPC (CPC Model 3772, TSI Inc., Shoreview, USA) typically agreed within $15 \%$ over the whole observation period at JFJ [35]. Due to its low data coverage, the MPSS data at JFJ was used to depict the mean PNSD in the PBL or FT conditions only for the year 2018, while a long-term trend of PNC for the period 20092018 was evaluated for site ZSF.

Atmospheric conditions referring to the FT and PBL were segregated using the approach described in Yuan et al. [42], with procedural details outlined below. The PNSD is bimodal typically in both Aitken and accumulation mode in the FT and PBL conditions, as shown in Fig. 2. Based on the shape of the PNSD at these two sites, the data were split into two modes: Aitken mode $(<80 \mathrm{~nm})$, and accumulation mode $(>80 \mathrm{~nm})$. Aitken mode particles observed at the high-Alpine site were mostly formed within the FT with a minor influence from vertical transport, while accumulation mode particles predominantly originate from vertical transport with a minor contribution from cloud processing induced particle growth [35].

\section{Trend analysis methods}

In this study, two trend detection methods were used: a non-parametric method seasonal Mann-Kendall (MK) test based on the original data and a parametric method generalized least-square-regression with auto-regressive bootstrap confidence intervals (GLS-ARB) based on logarithm data.

(1) Seasonal Mann-Kendal test associated with the Sen's slope.

The MK trend test is a statistical method that is widely used in the long-term trend detection of environmental data $[18,43]$. The MK trend test evaluates if there is a detectable monotonic increase or decrease in the evaluated time series. If there is, the Sen's slope and its confidence interval $(\mathrm{CI})$ are determined. However, most of the environmental time series present a seasonal cycle and consequently do not meet the required condition of homogeneity of the MK test. Then the seasonal MK test is used to detect the trend and an annual trend can only be considered if the seasonal trends are homogeneous $[44,45]$.
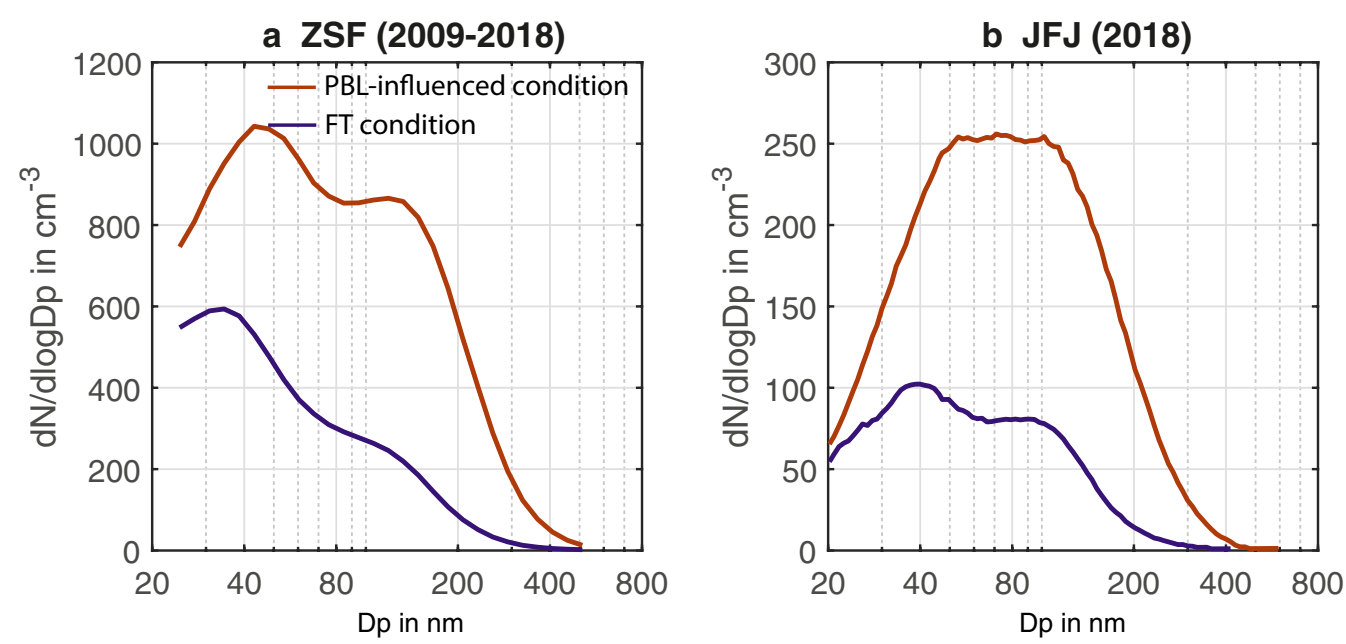

Fig. 2 The median PNSD for FT and PBL-influenced conditions at a ZSF (2009-2018) and b JFJ (entire 2018) 
For a time series $x(i)$ of length $n$, the MK statistic $S_{s}$ for each season $s$ is defined as

$$
S_{s}=\sum_{k=1}^{n-1} \sum_{j=k+1}^{n} \operatorname{sgn}(x(j)-x(k)),
$$

where

$$
\operatorname{sgn}(\theta)=\left\{\begin{array}{cc}
1 & \text { if } \theta>0 \\
0 & \text { if } \theta=0 \\
-1 & \text { if } \theta<0
\end{array}\right.
$$

Taking account of different seasons, the seasonal MK statistics $S$ is the sum of individual $S_{s}$ :

$$
S=\sum S_{s}
$$

For a large sample size $(n>10), S$ is converted to a normal test statistic $Z_{s}$ :

$$
Z_{s}=\left\{\begin{array}{cl}
\frac{S-1}{\delta_{s}} & \text { if } S>0 \\
0 & \text { if } S=0 \\
\frac{S+1}{\delta_{s}} & \text { if } S<0
\end{array}\right.
$$

where the standard deviation of $S$ is:

$$
\delta_{s}=\sqrt{\sum_{k=1}^{m}\left(n_{k} / 18\right)\left(n_{k}-1\right)\left(2 n_{k}+5\right)}
$$

and $n_{k}$ is the number of data in the $k$ th season.

In this study, the four meteorological seasons were used as temporal segmentations: (1) winter-from December to February; (2) spring-from March to May; (3) summer-from June to August; and (4) autumn-from September to November. A positive or negative $Z_{s}$ refers to a monotonic increasing or decreasing trend for each season $s$. The significance of the trend can be evaluated by a two-tail test. When the statistically significant trend is detected, the slope can be evaluated by Sen's slope estimator. For season $s$, the Sen's slope $m_{s}$ is:

$$
m_{s}=\frac{1}{n} \sum_{k=1}^{n-1} \sum_{j=k+1}^{n} \frac{x(j)-x(k)}{j-k} .
$$

The overall Sen's slope $m$ is the median of those $m_{s}$.

The MK trend test is not only robust for the statistical distribution, missing values, and outliers of observation data, but also very sensitive to the small trend [43]. However, the autocorrelation of the time series can bias the estimated MK trends. Pre-whitening methods are commonly used to diminish the bias caused by autocorrelation. Two free pre-whitening approaches, trend-free pre-whitening (TFPW) and variance-corrected trendfree pre-whitening (VCTFPW) were applied to assess the statistical significance of the trend, whereas a third prewhitening method correcting the variance in the time series was applied before the Sen's slope test to obtain a non-biased slope estimate [43]. In this method, the daily median was used as input data. The relative slope in \% per year was evaluated by dividing the absolute slope by the median concentration over the whole studied period to ensure the possibility for comparing the slopes between two different sites.

(2) Generalized least-square-regression and auto-regressive bootstrap confidence intervals (GLS-ARB)

The second method to evaluate the long-term trend of the parameter is the generalized least-square-regression (GLS) $[21,46]$. For a time series $x(i)$, we fit the time series by:

$$
x(i)=\beta_{1}+\beta_{2} t(i)+\Omega(t(i))+e(i),
$$

where $\beta_{1}$ and $\beta_{2}$ are two trend parameters (intercept and slope), $\Omega(t(i))$ refers to the seasonal components, and $e(i)$ is the random noise term.

Similar to other least-square-regression methods, the GLS computes the regression parameters $\boldsymbol{\beta}$ (trend and seasonal parameters) by minimizing the sum of squares of the error (SSQG):

$$
\operatorname{SSQG}(\boldsymbol{\beta})=(\boldsymbol{x}-\boldsymbol{t} \boldsymbol{\beta})^{\prime} \boldsymbol{V}^{-1}(\boldsymbol{x}-\boldsymbol{t} \boldsymbol{\beta}),
$$

where $\boldsymbol{t}$ is time, $\boldsymbol{x}$ is observation data, and $\boldsymbol{V}$ is the covariance matrix that can be estimated by Eq. (6) in Asmi et al. [21]. The CIs of the slopes were constructed by a resampling procedure, the auto-regressive bootstrap (ARB, algorithm 3.5 in Mudelsee [46]). In the resampling procedure, $e(i)$, the random noise term in Eq. (7) is resampled and a new time series is re-built with the original autocorrelation, trend, and seasonality. This procedure repeats 1000 times and 1000 new slopes can be calculated. The CIs of the slopes are obtained from these 1000 new slopes. Monthly median data were used in GLSARB. To obtain the normally distributed residuals as required by the GLS test, the logarithm of the data were applied to the GLS-ARB. The GLS-ARB indicates if a statistically significant (s.s.) decrease or increase is present.

\section{Separation of PBL and FT conditions}

Air from the FT and PBL is different concerning their distance in space and time from surface-related phenomena such as near-ground emissions and PBL convection. Consequently, the variations in aerosol concentrations resulting from atmospheric transport are assumed to be lower in the FT than in the PBL. 
There are several methods to distinguish the FT and PBL conditions by tracer or backward trajectories. The commonly used tracers to segregate FT and PBL include Radon [47], $\mathrm{NO}_{\mathrm{y}} / \mathrm{CO}[48,49]$, accumulation mode PNC [35], etc. Back trajectories can be also used to distinguish FT $[35,50]$. However, most of those approaches need a concentration threshold to extract FT conditions. It is worth noting that there is no precise distinction between FT and PBL conditions over complex terrain, and such choice of FT thresholds remains partly subjective [35].

In this study, the period with the lowest concentration and the least variation of the aerosol parameter at a given site was defined as the FT time. The FT conditions were extracted using the method adaptive diurnal minimum variation selection (ADVS) as described in Yuan et al. [42]. Briefly, based on the hourly time series, the 3-day detrended time series was calculated by subtracting a 3 -day average for each day. The overall mean diurnal cycle was then calculated from the detrended time series, named as "detrended diurnal cycle". Accordingly, a 6-h time window with the lowest standard deviation on the detrended diurnal cycle was selected as the default time window. In our study, a unified time window for both sites needs to be determined. By comparing the standard deviation on the detrended diurnal cycle at two sites, the time window (00:00-05:00 h local time) was defined as the default time window. Then, for each day, the standard deviation in the default time window was evaluated. If the variability was lower than a threshold, the site was considered to be within the FT during the default time window. The detected FT time window was examined in both forward and backward directions and extended, as long as the variability of neighboring time series values was below the threshold.

Two different thresholds were used in the ADVS for the two measurement sites. Sun et al. [20] showed that the $\mathrm{eBC}$ mass concentration decreased $-4.0 \%$ per year at ZSF during 2009-2018. Using the same trend detector as Sun et al. [20], the annual slope of the $\mathrm{eBC}$ mass concentration at JFJ is $-2.6 \%$ per year during $2009-2018$. A decreasing trend in concentration is expected to impose a concurrent decrease in standard deviation. Hence, we applied a time-dependent standard deviation threshold in the ADVS with a linear decrease matching the time trend of the concentration. This was done to avoid the variability-based FT criterion becoming more relaxed over time. The eBC mass variability thresholds were chosen to be $0.011 \mu \mathrm{g} \mathrm{m}^{-3}$ and $0.004 \mu \mathrm{g} \mathrm{m}^{-3}$ at ZSF and JFJ, respectively, for the year 2009 and with time gradients of $-4 \%$ and $-2.6 \%$ per year.

ADVS was previously applied to analyze the background $\mathrm{CO}_{2}$ concentration at high Alpine stations such as ZSF, JFJ, and Sonnblick [42, 51]. This is the first time that ADVS was used to extract the FT condition based on the $\mathrm{eBC}$ mass time series.

\section{Results and discussion \\ Diurnal cycle and seasonal differences in $\mathrm{EBC}$ and PNC}

Thermally driven vertical transport is one of the most decisive factors contributing to aerosol concentrations at high Alpine sites [35, 47, 52]. For example, transport from the PBL is mostly responsible for elevated BC mass concentrations [53], while on-site emissions related to tourism such as smoke, cooking, etc., only have a minor effect [33]. Figure 3 illustrates the median diurnal cycle of the measured parameters at ZSF and JFJ. The diurnal cycle was obtained by calculating the median concentration for each hour. To eliminate the seasonal variation of the meteorological condition, the diurnal cycle was plotted for the warm (from June to August) and cold (from December to February) seasons separately. As a general observation, higher concentration and stronger diurnal variability were observed in the warm season, while lower concentration and less distinct diurnal variability in the cold season (note the two seasons are plotted against separate $y$-axis with different scales). In the warm season, solar radiation is hitting the ground surface from a more perpendicular angle and longer duration. This warms near-surface air and causes convection that can reach to higher-altitudes. Thus, the vertical transport is more pronounced in the warm season compared to the cold season, leading to a higher concentration of aerosol particles at high-altitudes, especially for the vertical-transport-driven parameter such as $\mathrm{eBC}$ mass concentration and $N_{[80-510]}$. Moreover, the comparison of diurnal cycles during the cold season between the two sites revealed a stronger variation at ZSF than at JFJ for $\mathrm{eBC}$ mass concentration as well as for size-resolved PNC. This may suggest that some PBL influences occur at ZSF during the cold season, likely due to its lower altitude and topographical characteristics [54], whereas the JFJ site remains in the FT largely decoupled from the PBL influence.

\section{Identification of FT conditions}

As discussed above, thermally driven vertical transport is a crucial factor determining the $\mathrm{eBC}$ mass concentration and $N_{[80-510]}$ at high-altitudes. Since we have eBC mass concentration data available for both sites, we opted for the $\mathrm{eBC}$ mass concentration to identify the FT condition, in the framework of the ADVS method.

To validate the ADVS approach, we alternatively employed experimental radon $\left({ }^{222} \mathrm{Rn}\right)$ concentrations to segregate the PBL and FT conditions at the two sites. Radon is a short-lived radioactive gas that is naturally emitted from an ice-free surface such as rock and soil 

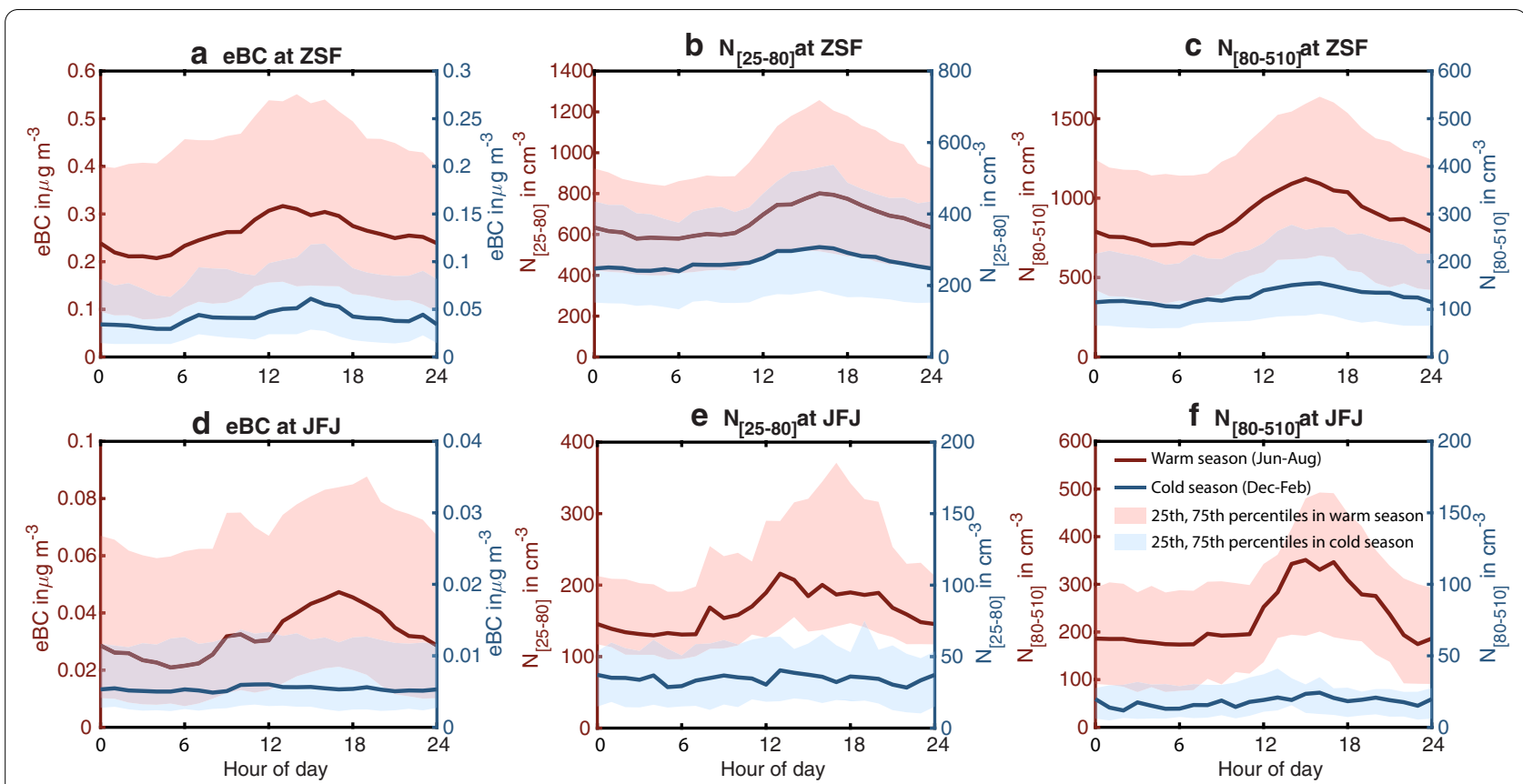

Fig. 3 The diurnal cycle of the eBC mass concentration and PNC for warm and cold seasons: $\mathbf{a}$ eBC at ZSF; $\mathbf{b} N_{[25-80]}$ at ZSF; $\mathbf{c} N_{[80-510]}$ at ZSF; $\mathbf{d}$ eBC at JFJ; e $N_{[25-80]}$ at JFJ; $\mathbf{f} N_{[80-510]}$ at JFJ

with a half-life of 3.8 days. Since it is non-reactive and poorly soluble in groundwater, ${ }^{222} \mathrm{Rn}$ is commonly used as a trace gas to identify air originating at lower-altitudes, where it escapes from the ground. Detailed instrumentation descriptions about ${ }^{222} \mathrm{Rn}$ measurement at ZSF and JFJ are provided in Frank et al. [55] and Chambers et al. [56]. In the Radon approach, a threshold of ${ }^{222} \mathrm{Rn}$ is usually needed to segregate the FT and PBL conditions. Herrmann et al. [35] reported the ${ }^{222} \mathrm{Rn}$ threshold of $0.67 \mathrm{~Bq} \mathrm{~m}^{-3}$ for the FT conditions at JFJ. A recent study on airmass classification at ZSF suggested that the ${ }^{222} \mathrm{Rn}$ concentration was around $1.3 \mathrm{~Bq} \mathrm{~m}^{-3}$ in unpolluted air [57]. Accordingly, we used 1.3 and $0.67 \mathrm{~Bq} \mathrm{~m}^{-3}$ as the ${ }^{222} \mathrm{Rn}$ threshold for ZSF and JFJ, respectively, to determine the FT condition. To ensure the comparability of the two approaches, we have further determined a time window of at least $6 \mathrm{~h}$ to select the FT period for radon. That is, if the ${ }^{222} \mathrm{Rn}$ falls below the given threshold continuously for at least $6 \mathrm{~h}$, the selected time window will be treated as the FT time.

The frequency of the FT condition derived by the two methods $\left({ }^{222} \mathrm{Rn}\right.$, and ADVS using eBC mass concentration as a tracer) is presented in Fig. 4. ADVS using $\mathrm{CO}_{2}$ as a trace gas at ZSF (presented in Yuan et al. [51]) is also illustrated for comparison. Since the radon measurements at both sites did not cover our whole observation period (2009-2018), we evaluated the FT frequencies at the two sites for the different time periods: 2012-2017 for ZSF, and 2009-2012 and 2016-2018 for JFJ. The FT conditions were more prevalent in winter (from December to February) than in summer for all methods. At ZSF, the frequencies of FT conditions were similar in winter among three approaches. However, in summer, higher FT prevalence was identified by the ${ }^{222} \mathrm{Rn}$ and $\mathrm{CO}_{2}$ approaches than our approach. At JFJ, the FT prevalence identified by the ${ }^{222} \mathrm{Rn}$ method was lower than that obtained by the ADVS (eBC) method. The difference between approaches may be attributed to the subjective choice of FT threshold. Nevertheless, the similarity of FT frequency values and seasonal patterns shown in Fig. 4 supports that all these approaches can be used as effective methods to segregate the FT and PBL conditions.

Figure 5 illustrates the diurnal occurrence of FT conditions for different seasons at the two sites. The diurnal occurrences show a similar pattern in different seasons at two sites: higher occurrence during midnight and lower during daytime. The highest frequencies of $\sim 50 \%$ and $70 \%$ at the ZSF and JFJ sites, respectively, were observed between midnight and early morning hours during winter. The FT prevalence was much lower during summer nights (only reaching $\sim 10 \%$ and $30 \%$ at ZSF and JFJ, respectively).

By comparing the FT conditions between the two sites, we found the FT periods evaluated at the two sites were sometimes different. Higher FT frequency was observed at JFJ than ZSF (Figs. 4 and 5), which may be due to the 


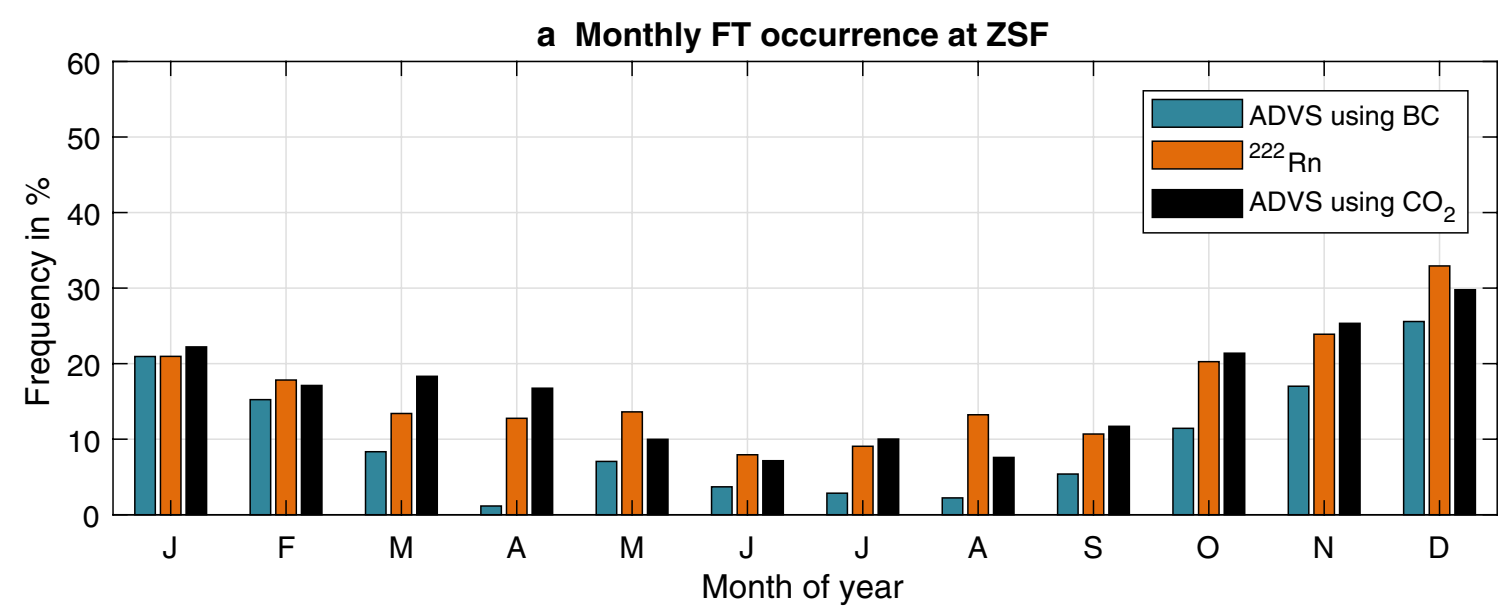

b Monthly FT occurrence at JFJ

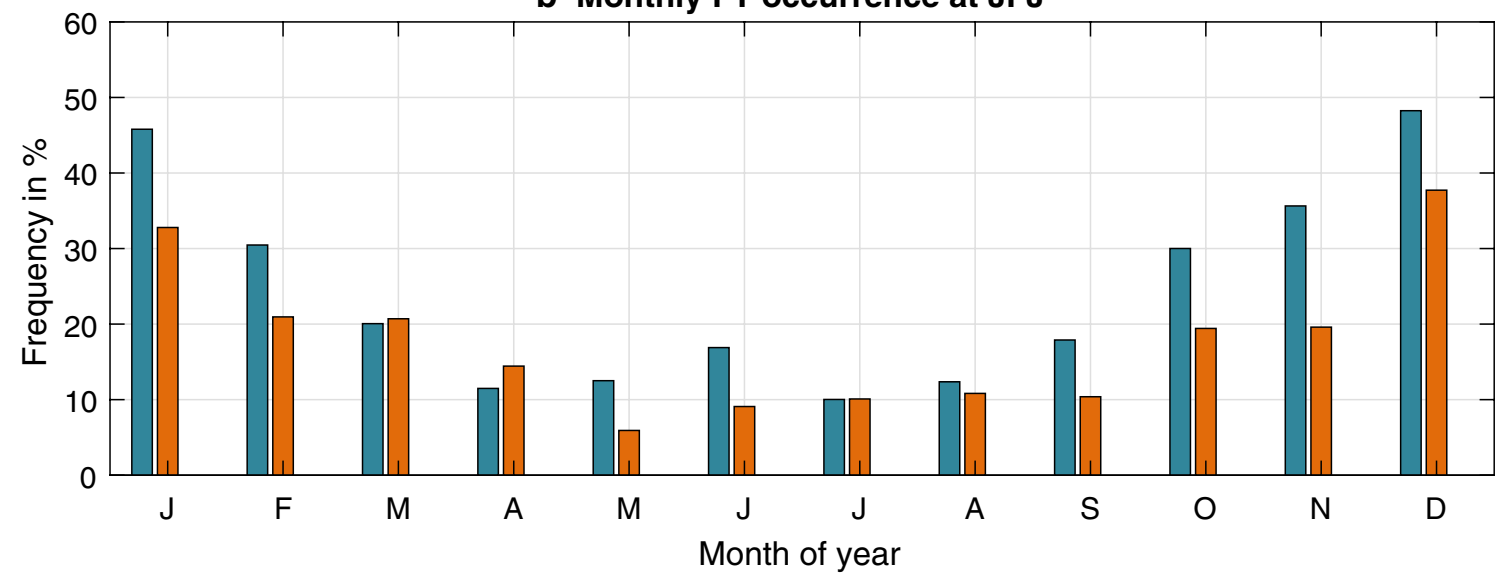

Fig. 4 The monthly occurrence of FT condition at ZSF (a) and JFJ (b) by three approaches: ADVS applied with eBC mass, ${ }^{222} \mathrm{Rn}_{1}$ and $A D V S$ with $\mathrm{CO}_{2}$

different topographic features between ZSF and JFJ. The influencing topographical features include, but are not limited to, altitude, local slope, hypsometric curve around observation site, etc. By evaluating the topographical features between ZSF and JFJ, ZSF was found to be more susceptible to vertical transport and stays in the PBL more frequently [54].

It is noteworthy that the FT frequency during 00:0005:00 shows a constant level. The reason for the similar frequency is that this time window (00:00-05:00 local time) is defined as the default time window in ADVS. Once the data in this default time window meet the criteria, all the hours between 00:00 and 05:00 will be recognized as FT conditions. Then the detected time window will be extended in both forward and backward directions. Therefore, we see the same occurrence of FT condition during the hours 00:00-05:00.

One important case of long-range transport influencing the aerosol concentration in the FT period is the Sahara dust events (SDE). SDE can be detected at ZSF and JFJ $[33,58,59]$. SDE can enhance $\mathrm{PM}_{10}$ mass concentration (mass concentration of aerosol particles with diameter $<10 \mu \mathrm{m})$ and $\mathrm{eBC}$ mass concentration resulting from biomass burning. When an SDE occurs, larger variations of aerosol concentrations may be observed in FT and it may not be detected as FT time in our ADVS detection process. Thus, SDE may influence the identification of the FT period, but we believe that the influence is small because of the following reasons: (1) the duration of the SDE is $>\sim 10 \mathrm{~h}$ and may usually last for 1-3 days $[58,59]$, which is longer than the time window of FT time detected by ADVS (6-10 h). Only if the change of the airmass occurred within the time window, it may cause a false identification. (2) the frequency of the SDE is low. SDE occurred about 5-15 times per year covering about 35 days every year during 1997-2013 in the Alps [59].

In the following sections, separated FT periods instead of the overlapping FT periods were used at the two sites to evaluate the temporal variations and trends of aerosol parameters. As can be seen in Fig. 4, only about $10 \%$ and 

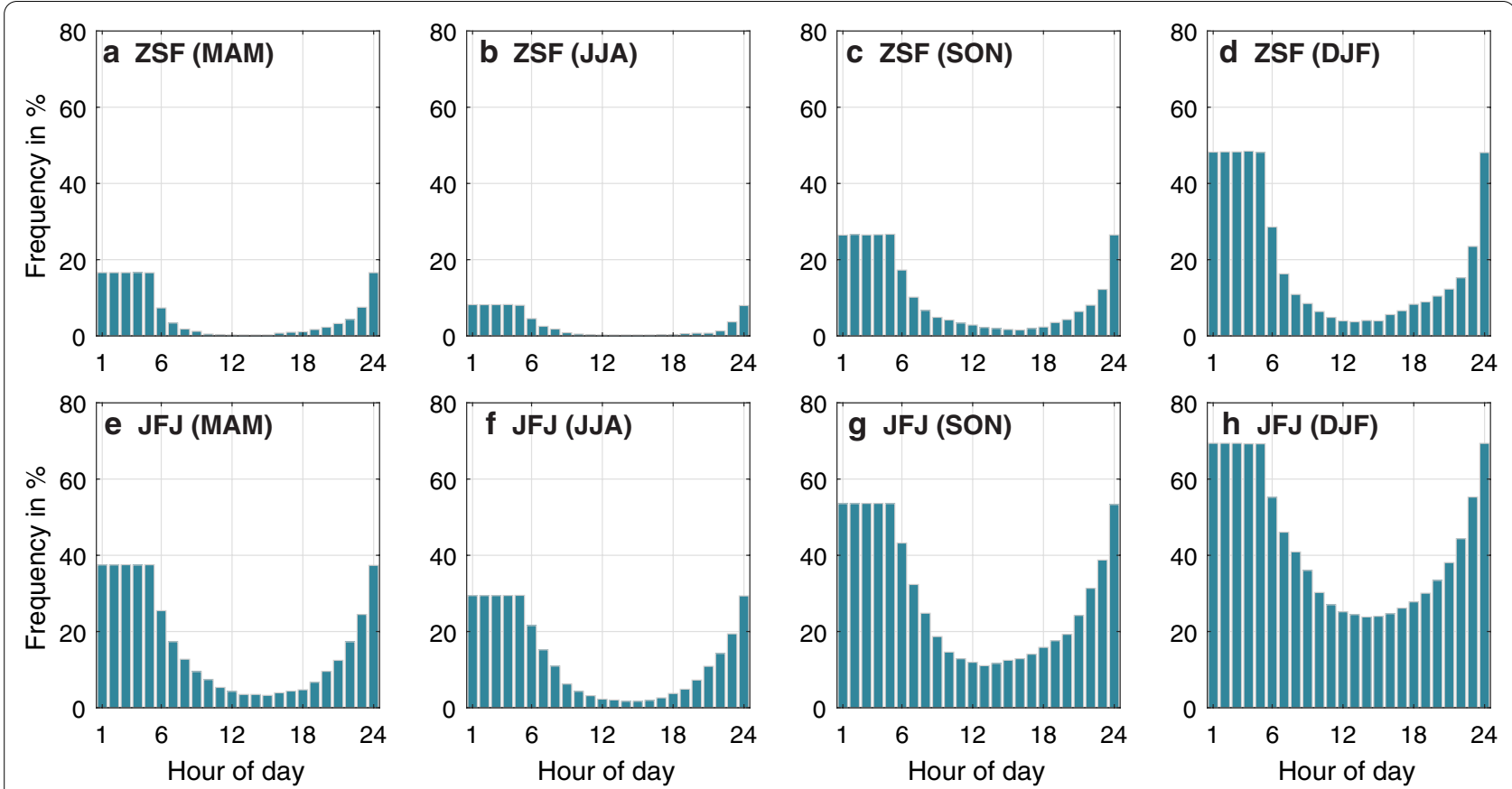

Fig. 5 The diurnal occurrence of FT condition in four seasons, calculated by the ADVS with eBC mass concentration: $\mathbf{a}$ at ZSF in spring (from March to May); $\boldsymbol{b}$ at ZSF in summer (from June to August); c at ZSF in autumn (from September to November); $\mathbf{d}$ at ZSF in winter (from December to February); $\mathbf{e}$ at JFJ in spring; $\mathbf{f}$ at JFJ in summer; $\mathbf{g}$ at JFJ in autumn; $\mathbf{h}$ at JFJ in winter

$30 \%$ periods were classified as FT condition at ZSF and JFJ, respectively. The overlapping periods of FT condition at ZSF and JFJ only account for $\sim 60 \%$ of the original FT periods at both sites. It means we will lose some data for the trend analysis if only the overlapping periods are used. Therefore, to obtain more robust trends, we decided to use separated FT periods for the two sites instead of the overlapping FT periods for trend analysis.

\section{Seasonal pattern segregated by FT and PBL influence}

The undisturbed FT conditions were identified by the ADVS method. The rest of the data not identified as undisturbed FT conditions are called hereafter as "PBLinfluenced condition". The PBL-influenced condition, for referring all other periods when the site is likely in the $\mathrm{PBL}$, in the residual layer, or in the PBL injection layer through mountain venting.

Figure 6 shows the annual cycle of the measured aerosol parameters separated by FT and PBL-influenced conditions for both sites. As described in the introduction section, the pollutants in the PBL have a higher chance to be transported to the high-altitudes than flat terrain. The pollutants in the FT are transported via synoptic airmass, or injected from the PBL injection layer, leading to a lower concentration and less distinct seasonal variation for the eBC mass concentration and $N_{[80-510]}$. By contrast, both concentration and amplitude of the seasonal cycle of $N_{[25-80]}$ were similar for the FT and PBL-influenced conditions at either site. This can be explained by the fact that $N_{[25-80]}$ is a local-source-driven parameter [60]. The maximum value of $N_{[25-80]}$ in the FT condition appeared from May to July, which may be explained by the seasonality of new particle formation events.

The maximum concentration of $N_{[80-510]}$ and eBC mass in the PBL-influenced condition was observed from July to August with a second peak in April and May. Moreover, a peak in April for the eBC mass concentration and $N_{[80-510]}$ were also seen in the FT condition. One possible explanation could be that convection weather dominates the Alps due to the increased surface temperature in April [52], leading to a higher aerosol loading and more frequent PBL injections at high-altitudes. From June to August, the convective weather becomes more predominant, leading to increased $\mathrm{eBC}$ mass concentrations and $\mathrm{PNC}$ [52]. However, the variations of the eBC mass concentration and $N_{[80-510]}$ were more distinct at ZSF than at JFJ, due to the stronger PBL influence at ZSF caused by its lower altitude and topographic features [54].

\section{Long-term trends of PNC and eBC mass concentration in the PBL-influenced condition}

Table 1 shows the annual slopes of the PNC and eBC mass concentration for the FT and PBL-influenced conditions for the period 2009-2018 for both sites using 


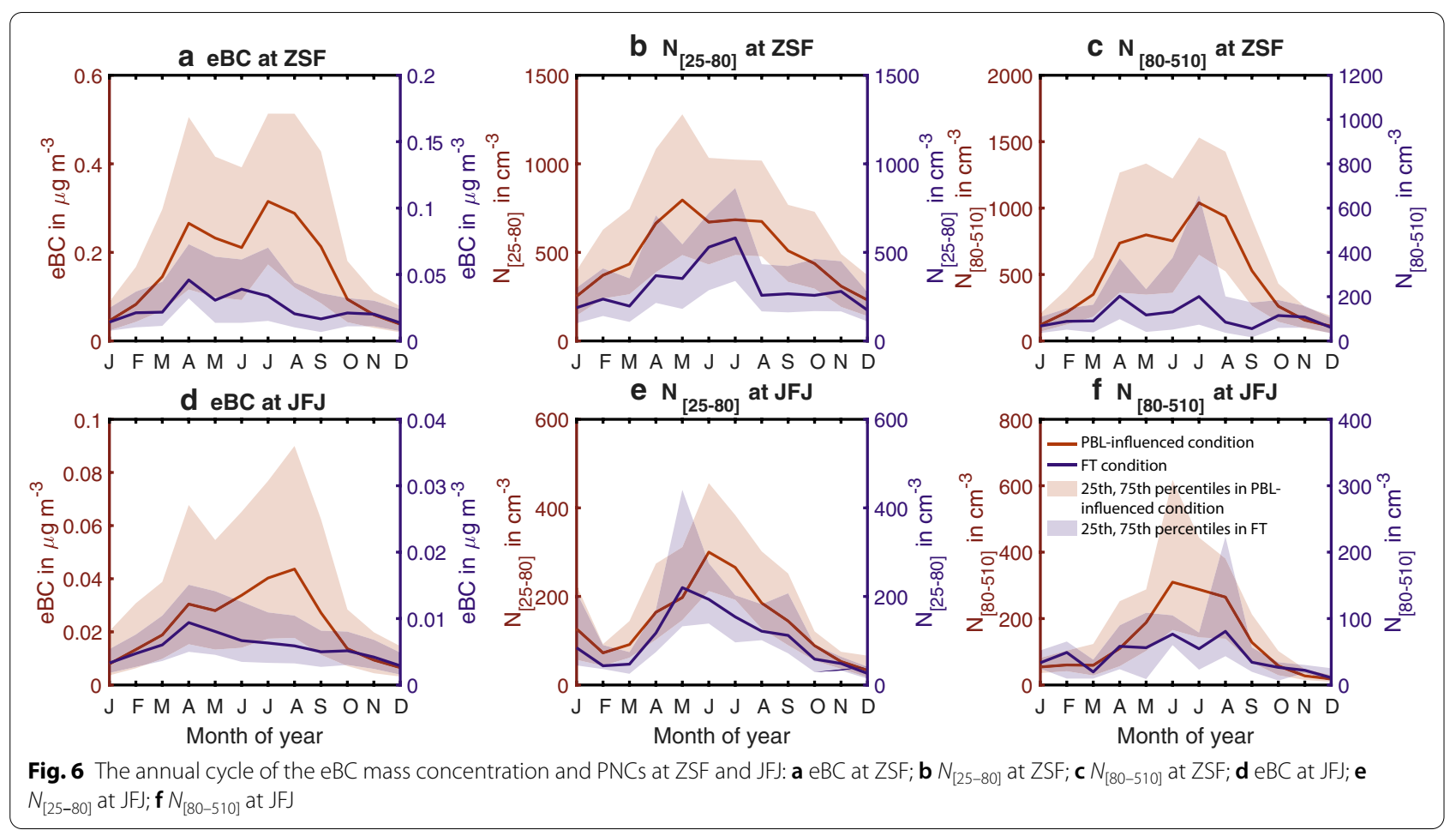

Table 1 The slopes, Cls, and statistical significances of the eBC mass concentration and PNC during 2009-2018, using two approaches: seasonal MK and GLS-ARB

\begin{tabular}{|c|c|c|c|c|c|}
\hline & \multicolumn{4}{|l|}{ Seasonal MK } & \multirow{2}{*}{$\begin{array}{l}\text { GLS-ARB } \\
\text { Trend of log (data }\end{array}$} \\
\hline & Slope (\%/year) & Cl (\%/year) & & Significance & \\
\hline \multicolumn{6}{|l|}{ PBL } \\
\hline \multicolumn{6}{|l|}{ ZSF } \\
\hline eBC & $-3.88 \%$ & $-10.15 \%$ & $0.56 \%$ & s.s. decrease & s.s. decrease \\
\hline$N_{[25-80]}$ & $-3.81 \%$ & $-5.42 \%$ & $-1.96 \%$ & s.s. decrease & s.s. decrease \\
\hline$N_{[80-510]}$ & $-4.96 \%$ & $-11.86 \%$ & $-0.84 \%$ & s.s. decrease & s.s. decrease \\
\hline \multicolumn{6}{|l|}{$J F J$} \\
\hline eBC & $-3.36 \%$ & $-8.71 \%$ & $-0.28 \%$ & s.s. decrease & s.s. decrease \\
\hline \multicolumn{6}{|l|}{ FT } \\
\hline \multicolumn{6}{|l|}{ ZSF } \\
\hline $\mathrm{eBC}$ & $-6.47 \%$ & $-20.32 \%$ & $8.86 \%$ & Not s.s. & s.s. decrease \\
\hline$N_{[25-80]}$ & $-8.73 \%$ & $-17.66 \%$ & $-0.25 \%$ & Not s.s. & s.s. decrease \\
\hline$N_{[80-510]}$ & $-7.23 \%$ & $-17.07 \%$ & $4.62 \%$ & Not s.s. & s.s. decrease \\
\hline \multicolumn{6}{|l|}{ JFJ } \\
\hline eBC & $-2.66 \%$ & $-9.81 \%$ & $3.61 \%$ & Not s.s. & s.s. decrease \\
\hline
\end{tabular}

The bold number shows the statistically significant (s.s.) slope at the $95 \%$ significance level

two trend detectors: Seasonal MK with original data and GLS-ARB with the logarithm of the data.

The eBC mass concentration and PNCs showed statistically significant (s.s.) decrease at the two sites due to vertical transport when the site was in the PBL-influenced condition. Many long-term studies conducted in
Europe have observed the s.s. decrease in aerosol variables (such as eBC mass concentration and PNC) in the lower-altitude area since 2000. The decrease in anthropogenic emissions caused by emission mitigation policies has been considered to be the main factor [20, 21, 28, 61]. According to the European Environment Agency 
(EEA) air pollutant emissions data [62], the total $\mathrm{BC}$ and $\mathrm{PM}_{10}$ emissions in Europe during 2009-2017 decreased by about $30 \%$ and $12 \%$, respectively. In Germany and Switzerland, where the two sites ZSF and JFJ are located, total $\mathrm{BC}$ emission decreased by about $30 \%$ and $35 \%$, respectively. It is noteworthy that the annual slope of $\mathrm{eBC}$ mass concentration in the PBL-influenced condition is $-3.88 \%$ and $-3.36 \%$ at ZSF and JFJ, respectively. Considering the evaluated period 2009-2018, the eBC mass concentration decreased about $38.8 \%$ and $33.6 \%$ at ZSF and JFJ, respectively. They are highly consistent with the decreases in total BC emission in Germany and Switzerland. This consistency indicates that the concentration of the aerosols transported to high-altitudes has correspondingly decreased in the absence of a temporal trend in vertical transport efficiency.

The change of weather conditions and long-range transport patterns may affect the long-term trend in aerosol variables. However, in our previous study [20], the inter-annual changes in weather conditions and synoptic-scale airmass conditions were not the reason for the decrease in aerosol concentrations in Germany during 2009-2018. These results indicate that the decrease in eBC mass concentration and PNC at ZSF and JFJ in the PBL-influenced condition was most likely caused by the decreased anthropogenic emissions in Europe.

\section{Long-term trends of PNC and $\mathrm{eBC}$ mass concentration in the FT condition}

In the FT condition, the $\mathrm{eBC}$ mass concentration and PNC at ZSF and JFJ had statistically insignificant decreased as detect by seasonal MK, while a statistically significant decrease was detected by GLS-ARB in all evaluated pollutant parameters. The daily median was used in the seasonal MK approach and the monthly median was used in GLS-ARB. In the FT condition, the daily median time series contained more missing values due to the lower FT prevalence, especially in the warm season. Moreover, the pollutant concentration in the FT condition was lower than in the PBL-influenced condition, sometimes even near to the detection limit. These two factors may result in a broad $\mathrm{CI}$ in the seasonal MK result. The noise in the data was larger for the FT conditions and this can explain the fact that the FT slopes were larger than the PBL slopes, but not statistically significant. The results suggest that the investigated aerosol parameters may have a decreasing trend in the FT conditions. However, the fewer number of data and increased noise might have hindered the exceedance of the statistical significance threshold despite a long period (10 years) of covered data. While there was no encountered difficulty when it comes to the s.s. trends for PBLinfluenced periods. The trends in the FT may indicate that the background aerosol concentration in the FT air over Central Europe has decreased during 2009-2018. This reduction may be affected by the decreased emission in the PBL, (and) or, the change of airmass pattern in the FT.

To further investigate other factors that may have affected the decreasing trends of the measured aerosol parameters in the FT condition, we extracted the airmass pattern at ZSF and JFJ in the FT condition and analyzed the aerosol concentration change for the different airmasses and the change of airmass frequency at the two sites.

The Hybrid Single-Particle Lagrangian Integrated Trajectory (HYSPLIT) model was used to determine the backward trajectories of airmasses arriving at ZSF and JFJ [63]. For each station, hourly backward trajectories were computed for the FT time during 2009-2018. The duration of trajectories was $96 \mathrm{~h}$ and the start height was $100 \mathrm{~m}$ above the ground on model terrain. It is noteworthy that the representativeness of HYSPLIT trajectories over complex terrain maybe not as good as over flat terrain. The meteorological forecast data in HYSPLIT has been spatially averaged, leading to a lower accuracy over complex terrain [64]. However, if the local wind flow is driven by the large-scale synoptic conditions, the HYSPLIT result is more accurate and can provide valid information [65].

The trajectories were classified into two clusters using the K-means clustering method. The basic statistics for the two airmass clusters are shown in Fig. 7. Cluster 1 is the regional airmass that has its origin over Central Europe, while cluster 2 is the long-range transport airmass. The height of airmass cluster 1 was significantly lower than the height of cluster 2 , which may indicate that the pollutants may be transported to the high Alpine sites via regional airmass when it enters the lower FT from PBL. As shown in Additional file 1: Fig. S1, the regional airmasses were mostly originated over Central Europe while long-range transport airmasses came from the Atlantic Ocean (west). The prevalence of the regional airmass was above $70 \%$ over the whole FT period for both two sites (Fig. 7c, d), which suggests that the FT condition that was evaluated in this study may be representative of the FT atmosphere over Central Europe.

Figure $7 \mathrm{e}, \mathrm{f}$ shows the averaged $\mathrm{eBC}$ mass concentration for the two airmass clusters. The eBC mass concentrations in the regional airmass were s.s. higher than in the long-range transport airmass. This indicates that regional-scale vertical transport under synoptic conditions corresponding to cluster 1 can raise the background aerosol concentration in FT, but without introducing concentration variability by the time measured at the high Alpine receptor sites. Moreover, the difference in 


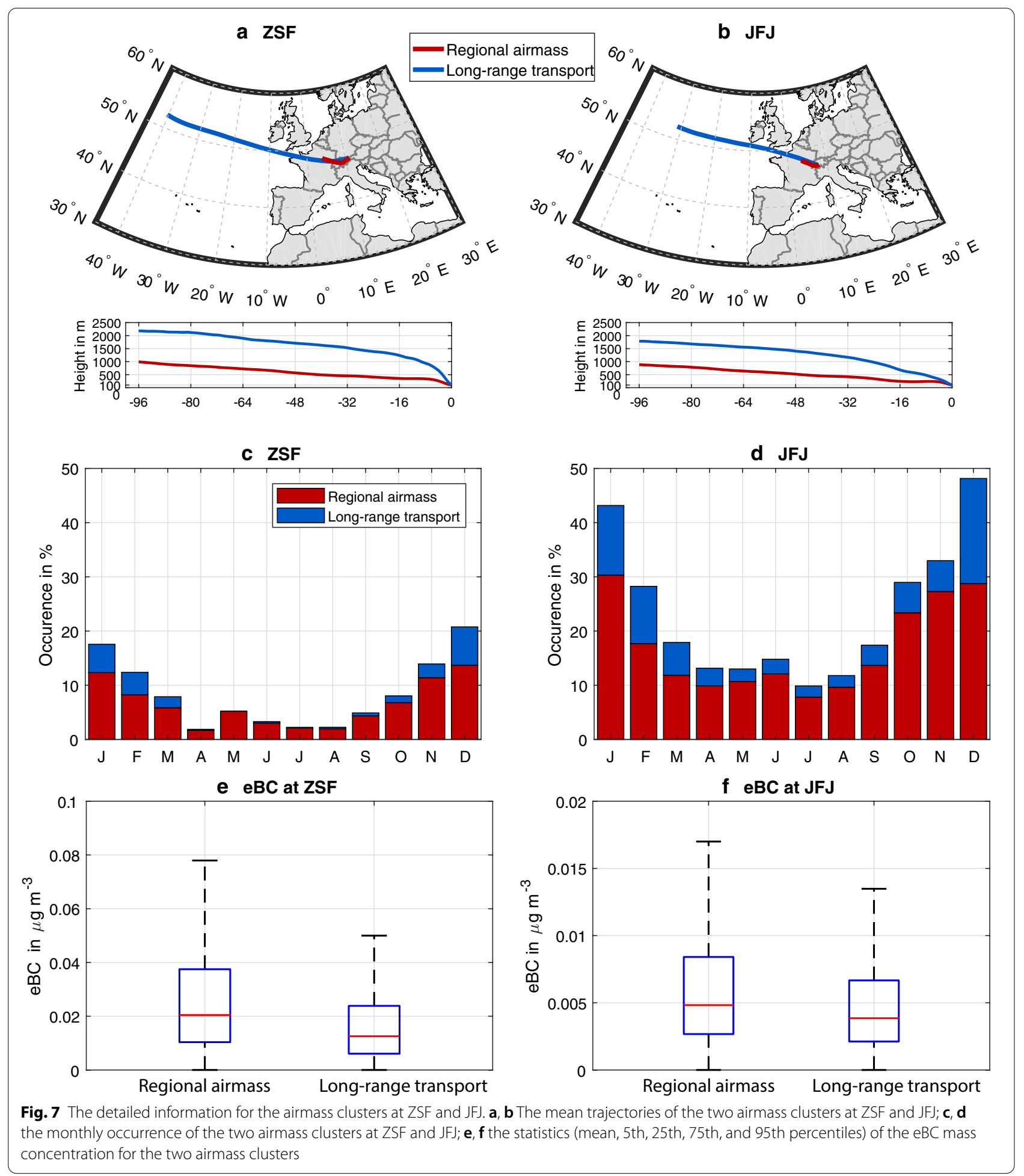

eBC mass concentration between two airmass clusters is more pronounced for ZSF. It is due to the stronger PBL influence at ZSF resulting from its lower altitude and topographical features [54].
Figure 8 illustrates the relative annual frequency of the two airmass clusters at ZSF and JFJ. In general, the change of airmass pattern at the two sites shows a similar result: the regional airmass shows a sudden drop 


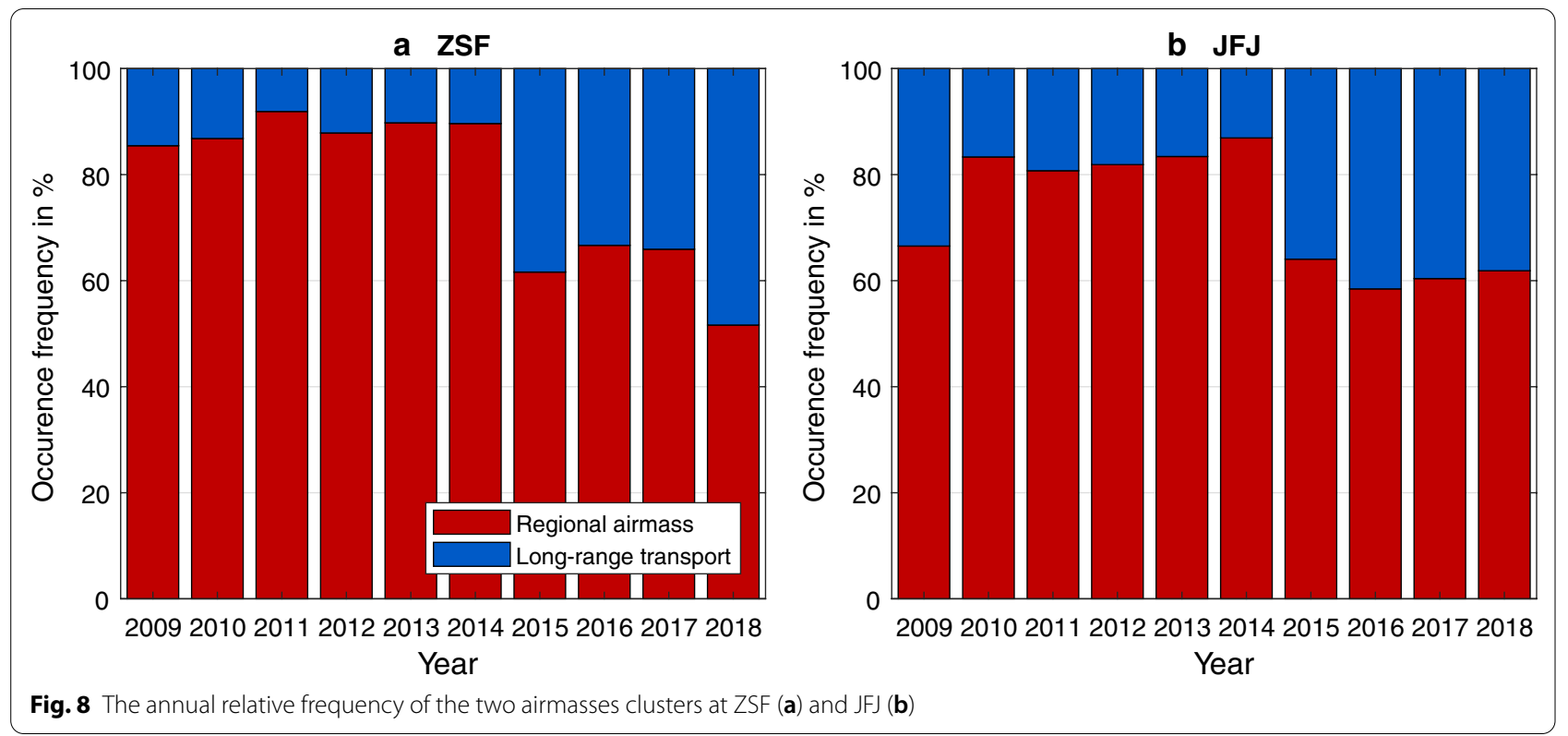

Table 2 The slopes, Cls, and statistical significances at the 95\% significance level for the eBC mass concentration in the regional airmass, using the seasonal MK method

\begin{tabular}{lllll}
\hline & Slope (\%/year) & Cl (\%/year) & & Significance \\
\hline ZSF & -3.94 & -20.71 & 12.29 & Not s.s. \\
JFJ & -2.21 & -10.72 & 5.90 & Not s.s. \\
\hline
\end{tabular}

after 2015 at both two sites. This drop may occur if the FT periods (or airmasses data) in a particular season are missing after 2015. As shown in Additional file 1: Fig. S2, no seasonal change in FT time can be observed after 2015 and it cannot explain the sudden drop in Fig. 8. But we do not know the exact reason for this drop. So, we speculate that it may be due to the short-term climate change, or circulation changes.

Fewer regional airmasses reaching ZSF and JFJ after 2015 resulted in fewer pollutants can be transported to ZSF and JFJ. This could be one of the explanations for the decreased pollutant concentration in the FT condition. However, the difference still can be seen between the two sites. Fewer regional airmasses were detected at JFJ than at ZSF before 2015. But the relative frequency of regional airmass was at a similar level (about 60\%) at the two sites after 2015. This suggests that the decrease of regional airmass occurrence was stronger at ZSF than at JFJ, leading to the stronger decrease of aerosol concentration at ZSF in the FT condition as shown in Table 1.

The trend of the $\mathrm{eBC}$ mass concentration in the regional airmass is shown in Table 2. The trends in the
$\mathrm{eBC}$ mass concentration in the long-range transport airmass were not evaluated due to its low data coverage. As shown in Table 2, insignificant decreases were detected in the regional airmass at the two sites. Like the seasonal MK slopes in the FT condition in Table 1, we consider the $\mathrm{eBC}$ mass concentration in the regional airmass was decreasing during 2009-2018, but insignificant slopes shown in Table 2 may also result from the low data coverage and low aerosol concentrations. This result and the decreasing trends in PBL-influenced conditions can both suggest the reduction of emissions over Central Europe is the most decisive factor for the decreased aerosol concentration in lower FT at the two sites. Fewer regional airmasses reaching ZSF and JFJ after 2015 can be another driver for the decreasing trends.

\section{Conclusions}

Long-term observations at high-altitudes provide an opportunity to detect changes in pollutant concentration in both the free troposphere (FT) and the planetary boundary layer (PBL). In this study the long-term change in the equivalent black carbon $(\mathrm{eBC})$ mass concentration and size-resolved particle number concentrations (PNCs) were determined in two high Alpine stations: ZugspitzeSchneefernerhaus (ZSF, $2671 \mathrm{~m}$ a.s.l.) in Germany and Jungfraujoch (JFJ, $3580 \mathrm{~m}$ a.s.l.) in Switzerland during 2009-2018.

To segregate the FT and PBL conditions at the two sites, the method, Adaptive Diurnal minimum Variation Selection (ADVS) was applied, using the eBC mass concentration as a tracer. The result showed that the 
FT condition in the cold months was more prevalent than in the warm months. Overall, the FT frequency was $\sim 25 \%$ and $6 \%$ in the cold and warm seasons at ZSF, respectively. At JFJ, the frequency of FT was $\sim 45 \%$ and $10 \%$ in these two seasons.

In the PBL-influenced condition, all the aerosol parameters showed a statistically significant (s.s.) decrease. Aerosol particles can be transported to the high-altitudes via vertical transport when the site is in the PBL or the PBL injection layer. The decrease in eBC mass concentration and PNC at ZSF and JFJ in the PBL-influenced condition may be most likely caused by the decreased anthropogenic emission over Central Europe.

In the FT condition, the decreasing trend in the $\mathrm{eBC}$ mass concentration and PNC at the two sites were detected, indicating the background aerosol concentration in the FT over Central Europe has decreased during 2009-2018. The Hybrid Single-Particle Lagrangian Integrated Trajectory (HYSPLIT) model was used to determine the backward trajectories and to estimate the pathways of the airmass arrived at ZSF and JFJ to detect the possible influencing factors affecting the decreased aerosol concentration in the FT conditions. Two airmass clusters were detected: regional airmass from Central Europe and long-range transport airmass from the Atlantic Ocean (west). The occurrence of regional airmass decreased during 2009-2018 and the $\mathrm{eBC}$ mass concentration in the regional airmass cluster also showed a decreasing trend. These two factors may be considered as two of the drivers for the decreasing trend of aerosol concentration in the FT condition. The implementation of emission mitigation policies is the most decisive factor and the decrease of the regional airmass occurrence over Central Europe also has contributed to the decreasing trends.

\footnotetext{
Abbreviations

FT: Free troposphere; PBL: Planetary boundary layer; JFJ: Jungfraujoch; ZSF: Zugspitze-Schneefernerhaus; PNC: Particle number concentration; BC: Black carbon; eBC: Equivalent black carbon; ${ }^{222}$ Rn: Radon; ADVS: Adaptive diurnal minimum variation selection; WMO: World Meteorological Organization; GAW :WMO's Global Atmosphere Watch; ACTRIS: Aerosols, Clouds and Trace gases Research InfraStructure Network; GUAN: German ultrafine aerosol network; MAAP: Multi-angle absorption photometer; MAC: Mass absorption crosssection; MPSS: Mobility particle size spectrometer; PNSD: Particle number size distribution; DMA: Differential mobility analyzer; CPC: Condensation particle counter; GLS: Generalized least-square-regression; ARB: Auto-regressive bootstrap; Cl: Confidence interval; MK: Mann-Kendall test; s.s.: Statistically significant; TFPW: Trend-free pre-whitening; VCTFPW: Variance-corrected trendfree pre-whitening; SSQG: The sum of squares of the error; EEA: European Environment Agency; HYSPLIT: Hybrid Single-Particle Lagrangian Integrated Trajectory; SDE: Sahara dust events; $\mathrm{PM}_{10}$ : Mass concentration of aerosol particles with diameter $<10 \mu \mathrm{m}$.
}

\section{Supplementary Information}

The online version contains supplementary material available at https://doi. org/10.1186/s12302-021-00488-w.

Additional file 1. Figure S1. The frequency distribution of starting point for the two airmass clusters: (a) regional airmass at ZSF; (b) long-range airmass at ZSF; (c) regional airmass at JFJ; (d) long-range airmass at JFJ. Figure S2. The annual relative FT frequency for different seasons at ZSF (a) and JFJ (b).

\section{Acknowledgements}

We acknowledge funding by the Virtual Alpine Observatory II (VAO II) project from the German Environment Agency (UBA) on behalf of the German Ministry for Environment as well as from the Bavarian State Ministry of the Environment and Consumer. Measurements at ZSF were supported by the German Federal Ministry for the Environment, Nature Conservation, and Nuclear Safety (BMU) grants F\&E 370343200 (2008-2010) and F\&E 371143232 (2012-2014). Radon measurements at ZSF were made available from Thomas Elste, Deutscher Wetterdienst (DWD), and through the WMO Global Atmosphere Watch World Data Centre for Greenhouse Gases (WDCGG, https:// gaw.kishou.go.jp/). The aerosol measurements at the JFJ site were supported by MeteoSwiss in the framework of the Swiss contributions (GAW-CH and GAW-CH-Plus) to the Global Atmosphere Watch programme of the World Meteorological Organization (WMO), and the Swiss State Secretariat for Education, Research and Innovation, SERI, under contract number 15.0159-1 (ACTRIS-2); the opinions expressed and arguments employed herein do not necessarily reflect the official views of the Swiss Government. We also thank Dr. Franz Conen for the contribution of Radon data at JFJ. The International Foundation High Altitude Research Stations JFJ and Gornergrat (HFSJG) for providing through its infrastructure the possibility to measure aerosols and radon concentrations at JFJ, and the Swiss contribution to ICOS (https://www. icos-ri.eu) for financially supporting the operation of the radon detector. The authors would like to thank André Sonntag (TROPOS) contributed to data processing at ZSF.

This work was also accomplished in the frame of the project ACTRIS-2 (Aerosols, Clouds, and Trace gases Research InfraStructure) under the European Union-Research Infrastructure Action in the frame of the H2020 program for "Integrating and opening existing national and regional research infrastructures of European interest" under Grant Agreement N654109 (Horizon 2020). Additionally, we acknowledge the WCCAP (World Calibration Centre for Aerosol Physics) as part of the WMO-GAW program base-funded by the UBA for data quality assurance.

\section{Authors' contributions}

AW, NM, WB, MH, and JS designed the research. JS, YY, and MCC conducted the data analysis. TT, KW, LR, RS, CC, GF, and BTB conducted the measurements. JS and NM wrote the paper with input from all co-authors. LM, LP and MGB participated in the discussion of the data analysis. All authors read and approved the final manuscript.

\section{Funding}

This research has been funded by the Virtual Alpine Observatory II (VAO II) project from the German Environment Agency (UBA) on behalf of the German Ministry for Environment as well as from the Bavarian State Ministry of the Environment and Consumer, award number: VAO II-TP I/02.

\section{Availability of data and materials}

Data and material are available from the GUAN, GAW WDCGG, and the German Environment Agency.

\section{Declarations}

Ethics approval and consent to participate Not applicable.

Consent for publication

It is declared that consent for publication exists. 


\section{Competing interests}

The authors declare that they have no competing interests.

\section{Author details}

${ }^{1}$ Leibniz Institute for Tropospheric Research (TROPOS), Leipzig, Germany.

${ }^{2}$ TUM School of Life Sciences, Technical University of Munich (TUM), Freising, Germany. ${ }^{3}$ German Environment Agency (UBA), Dessau-Roßlau, Germany.

${ }^{4}$ Federal Office of Meteorology and Climatology, MeteoSwiss, Payerne, Switzerland. ${ }^{5}$ German Environment Agency (UBA), Zugspitze, Germany. ${ }^{6}$ Deutscher Wetterdienst (DWD), Offenbach, Germany. ${ }^{7}$ Laboratory of Atmospheric Chemistry, Paul Scherrer Institute, Villigen PSI, Switzerland. ${ }^{8}$ Institute for Environmental and Climate Research, Jinan University, Guangzhou, China.

Received: 4 November 2020 Accepted: 24 March 2021

Published online: 15 April 2021

\section{References}

1. Van Dingenen R et al (2004) A European aerosol phenomenology-1: physical characteristics of particulate matter at kerbside, urban, rural and background sites in Europe. Atmos Environ 38(16):2561-2577. https://doi. org/10.1016/j.atmosenv.2004.01.040

2. Merikanto J et al (2009) Impact of nucleation on global CCN. Atmos Chem Phys 9(21):8601-8616. https://doi.org/10.5194/acp-9-8601-2009

3. Pierce JR et al (2009) Uncertainty in global CCN concentrations from uncertain aerosol nucleation and primary emission rates. Atmos Chem Phys 9(4):1339-1356. https://doi.org/10.5194/acp-9-1339-2009

4. Ramachandran S et al (2007) Black carbon aerosol mass concentrations over Ahmedabad, an urban location in western India: comparison with urban sites in Asia, Europe, Canada, and the United States. J Geophys Res Atmos. https://doi.org/10.1029/2006JD007488

5. Samset BH et al (2011) Vertical dependence of black carbon, sulphate and biomass burning aerosol radiative forcing. Geophys Res Lett. https:// doi.org/10.1029/2011GL049697

6. Sanroma E et al (2010) Long-term changes in insolation and temperatures at different altitudes. Environ Res Lett 5(2):024006. https://doi.org/ 10.1088/1748-9326/5/2/024006

7. Zarzycki CM et al (2010) How much can the vertical distribution of black carbon affect its global direct radiative forcing? Geophys Res Lett. https:// doi.org/10.1029/2010GL044555

8. Motos $\mathrm{G}$ et al (2019) Cloud droplet activation properties and scavenged fraction of black carbon in liquid-phase clouds at the highalpine research station Jungfraujoch (3580 m a.s.l.). Atmos Chem Phys 19(6):3833-3855. https://doi.org/10.5194/acp-19-3833-2019

9. Hansen J et al (1997) Radiative forcing and climate response. J Geophys Res Atmos 102(D6):6831-6864. https://doi.org/10.1029/96jd03436

10. Koch D et al (2010) Black carbon semi-direct effects on cloud cover: review and synthesis. Atmos Chem Phys 10(16):7685-7696

11. Birmili W et al (2010) A case of transatlantic aerosol transport detected at the Schneefernerhaus Observatory (2650 m) on the northern edge of the Alps. Meteorol Z 19(6):591-600. https://doi.org/10.1127/0941-2948/2010/ 0465

12. Mattis I et al (2008) Ten years of multiwavelength Raman lidar observations of free-tropospheric aerosol layers over central Europe: geometrical properties and annual cycle. J Geophys Res Atmos. https://doi.org/10. 1029/2007jd009636

13. De Wekker SFJ et al (2015) Convective boundary layer heights over mountainous terrain-a review of concepts. Front Earth Sci. https://doi. org/10.3389/feart.2015.00077

14. Henne S et al (2004) Quantification of topographic venting of boundary layer air to the free troposphere. Atmos Chem Phys 4(2):497-509. https:// doi.org/10.5194/acp-4-497-2004

15. Poltera $Y$ et al (2017) PathfinderTURB: an automatic boundary layer algorithm. Development, validation and application to study the impact on in situ measurements at the Jungfraujoch. Atmos Chem Phys 17(16):10051-10070. https://doi.org/10.5194/acp-17-10051-2017

16. European Environment Agency (2018) Air quality in Europe-2018 report. p. 83.
17. Bigi $A$ et al (2016) Trends and variability of atmospheric $P M_{2.5}$ and $P_{10-2.5}$ concentration in the Po Valley. Italy. Atmos Chem Phys 16(24):1577715788. https://doi.org/10.5194/acp-16-15777-2016

18. Pandolfi M et al (2016) Trends analysis of PM source contributions and chemical tracers in NE Spain during 2004-2014: a multi-exponential approach. Atmos Chem Phys 16(18):11787-11805. https://doi.org/10. 5194/acp-16-11787-2016

19. Singh $V$ et al (2018) Trends of atmospheric black carbon concentration over the United Kingdom. Atmos Environ 178:148-157. https://doi.org/ 10.1016/j.atmosenv.2018.01.030

20. Sun J et al (2020) Decreasing trends of particle number and black carbon mass concentrations at 16 observational sites in Germany from 2009 to 2018. Atmos Chem Phys 20(11):7049-7068. https://doi.org/10.5194/ acp-20-7049-2020

21. Asmi A et al (2013) Aerosol decadal trends-part 2: In-situ aerosol particle number concentrations at GAW and ACTRIS stations. Atmos Chem Phys 13(2):895-916. https://doi.org/10.5194/acp-13-895-2013

22. Collaud Coen M et al (2020) Multidecadal trend analysis of in situ aerosol radiative properties around the world. Atmos Chem Phys 20(14):88678908. https://doi.org/10.5194/acp-20-8867-2020

23. Collaud Coen M et al (2013) Aerosol decadal trends - part 1: in-situ optical measurements at GAW and IMPROVE stations. Atmos Chem Phys 13(2):869-894. https://doi.org/10.5194/acp-13-869-2013

24. Ahmed T et al (2014) Long term trends in Black Carbon Concentrations in the Northeastern United States. Atmos Res 137:49-57. https://doi.org/10. 1016/j.atmosres.2013.10.003

25. Barmpadimos I et al (2011) Influence of meteorology on $\mathrm{PM}_{10}$ trends and variability in Switzerland from 1991 to 2008. Atmos Chem Phys 11(4):1813-1835. https://doi.org/10.5194/acp-11-1813-2011

26. Saylor R et al (2014) Recent trends in gas-phase ammonia and $\mathrm{PM}_{2.5}$ ammonium in the Southeast United States. J Air Waste Manage Assoc 65(3):347-357. https://doi.org/10.1080/10962247.2014.992554

27. Stelcer E et al (2014) Long term $\mathrm{PM}_{25}$ trends in the Australian industrial city of Newcastle: a 15-year study from 1998 to 2013. Environ Chem 11(6):644-652. https://doi.org/10.1071/en14090

28. Kutzner RD et al (2018) Long-term monitoring of black carbon across Germany. Atmos Environ 185:41-52. https://doi.org/10.1016/j.atmosenv. 2018.04.039

29. Putaud J et al (2014) Long-term trends in aerosol optical characteristics in the Po Valley, Italy. Atmos Chem Phys 14(17):9129-9136

30. Collaud Coen M et al (2007) Long-term trend analysis of aerosol variables at the high-alpine site Jungfraujoch. J Geophys Res Atmos (1984-2012). https://doi.org/10.1029/2006JD007995

31. Giemsa E et al (2019) Investigating regional source and sink patterns of Alpine $\mathrm{CO}_{2}$ and $\mathrm{CH}_{4}$ concentrations based on a back trajectory receptor model. Environ Sci Eur 31(1):49. https://doi.org/10.1186/ s12302-019-0233-x

32. Risius $S$ et al (2015) Schneefernerhaus as a mountain research station for clouds and turbulence. Atmos Meas Tech 8(8):3209-3218. https://doi.org/ 10.5194/amt-8-3209-2015

33. Bukowiecki $\mathrm{N}$ et al (2016) A review of more than 20 years of aerosol observation at the high altitude research station Jungfraujoch, Switzerland (3580 m asl). Aerosol Air Qual Res 16:764-788

34. Collaud Coen M et al (2014) Determination and climatology of the planetary boundary layer height above the Swiss plateau by in situ and remote sensing measurements as well as by the COSMO-2 model. Atmos Chem Phys 14(23):13205-13221. https://doi.org/10.5194/acp-14-13205-2014

35. Herrmann E et al (2015) Analysis of long-term aerosol size distribution data from Jungfraujoch with emphasis on free tropospheric conditions, cloud influence, and air mass transport. J Geophys Res Atmos 120(18):9459-9480. https://doi.org/10.1002/2015JD023660

36. Jurányi Z et al (2011) A 17 month climatology of the cloud condensation nuclei number concentration at the high alpine site Jungfraujoch. J Geophys Res Atmos. https://doi.org/10.1029/2010JD015199

37. Müller T et al (2011) Characterization and intercomparison of aerosol absorption photometers: result of two intercomparison workshops. Atmos Meas Tech 4(2):245-268. https://doi.org/10.5194/amt-4-245-2011

38. Petzold A et al (2004) Multi-angle absorption photometry-a new method for the measurement of aerosol light absorption and atmospheric black carbon. J Aerosol Sci 35(4):421-441 
39. Zanatta M et al (2016) A European aerosol phenomenology-5: Climatology of black carbon optical properties at 9 regional background sites across Europe. Atmos Environ 145:346-364. https://doi.org/10.1016/j. atmosenv.2016.09.035

40. Birmili W et al (2016) Long-term observations of tropospheric particle number size distributions and equivalent black carbon mass concentrations in the German Ultrafine Aerosol Network (GUAN). Earth Syst Sci Data 8(2):355-382. https://doi.org/10.5194/essd-8-355-2016

41. Wiedensohler A et al (2012) Mobility particle size spectrometers: harmonization of technical standards and data structure to facilitate high quality long-term observations of atmospheric particle number size distributions. Atmos Meas Tech 5(3):657-685. https://doi.org/10.5194/ amt-5-657-2012

42. Yuan $\mathrm{Y}$ et al (2018) Adaptive selection of diurnal minimum variation: a statistical strategy to obtain representative atmospheric $\mathrm{CO}_{2}$ data and its application to European elevated mountain stations. Atmos Meas Tech 11(3):1501-1514. https://doi.org/10.5194/amt-11-1501-2018

43. Collaud Coen M et al (2020) Effects of the prewhitening method, the time granularity and the time segmentation on the Mann-Kendall trend detection and the associated Sen's slope. Atmos Meas Tech 13:69456964. https://doi.org/10.5194/amt-13-6945-2020

44. Hirsch RM et al (1984) A nonparametric trend test for seasonal data with serial dependence. Water Resour Res 20(6):727-732. https://doi.org/10. 1029/WR020i006p00727

45. Hirsch RM et al (1982) Techniques of trend analysis for monthly waterquality data. Water Resour Res 18(1):107-121. https://doi.org/10.1029/ WR018i001p00107

46. Mudelsee M (2010) Climate time series analysis: classical statistical and bootstrap methods. Springer, Berlin

47. Griffiths AD et al (2014) Surface-to-mountaintop transport characterised by radon observations at the Jungfraujoch. Atmos Chem Phys 14(23):12763-12779. https://doi.org/10.5194/acp-14-12763-2014

48. Pandey Deolal S et al (2013) Transport of PAN and NOy from different source regions to the Swiss high alpine site Jungfraujoch. Atmos Environ 64:103-115. https://doi.org/10.1016/j.atmosenv.2012.08.021

49. Zellweger $\mathrm{C}$ et al (2003) Partitioning of reactive nitrogen $\left(\mathrm{NO}_{\mathrm{y}}\right)$ and dependence on meteorological conditions in the lower free troposphere. Atmos Chem Phys 3(3):779-796. https://doi.org/10.5194/acp-3-779-2003

50. Balzani Lööv JM et al (2008) Estimation of background concentrations of trace gases at the Swiss Alpine site Jungfraujoch (3580 m asl). J Geophys Res Atmos. https://doi.org/10.1029/2007JD009751

51. Yuan Y et al (2019) On the diurnal, weekly, and seasonal cycles and annual trends in atmospheric $\mathrm{CO}_{2}$ at Mount Zugspitze, Germany, during 1981-2016. Atmos Chem Phys 19(2):999-1012. https://doi.org/10.5194/ acp-19-999-2019

52. Collaud Coen M et al (2011) Aerosol climatology and planetary boundary influence at the Jungfraujoch analyzed by synoptic weather types. Atmos Chem Phys 11(12):5931-5944. https://doi.org/10.5194/acp-11-5931-2011

53. Motos $\mathrm{G}$ et al (2020) Black carbon aerosols in the lower free troposphere are heavily coated in summer but largely uncoated in winter at
Jungfraujoch in the Swiss Alps. Geophys Res Lett 47(14):e2020GL088011. https://doi.org/10.1029/2020gl088011

54. Collaud Coen M et al (2018) Identification of topographic features influencing aerosol observations at high altitude stations. Atmos Chem Phys 18(16):12289-12313. https://doi.org/10.5194/acp-18-12289-2018

55. Frank G et al (2012) Messung radioaktiver Spurenstoffe in der Atmosphäre im Rahmen des Global Atmosphere Watch Programmes der WMO Wissenschaftliche Resultate 2011/2012: Umweltforschungsstation Schneefernerhaus.

56. Chambers SD et al (2016) Towards a universal "Baseline" characterisation of air masses for high- and low-altitude observing stations using radon222. Aerosol Air Qual Res 16(3):885-899. https://doi.org/10.4209/aaqr. 2015.06.0391

57. Sigmund A et al (2019) Multivariate statistical air mass classification for the high-alpine observatory at the Zugspitze Mountain, Germany. Atmos Chem Phys 19(19):12477-12494. https://doi.org/10.5194/ acp-19-12477-2019

58. Collaud Coen M et al (2004) Saharan dust events at the Jungfraujoch: detection by wavelength dependence of the single scattering albedo and first climatology analysis. Atmos Chem Phys 4(11/12):2465-2480. https://doi.org/10.5194/acp-4-2465-2004

59. Flentje $\mathrm{H}$ et al (2015) Identification and monitoring of Saharan dust: an inventory representative for south Germany since 1997. Atmos Environ. https://doi.org/10.1016/j.atmosenv.2015.02.023

60. Sun J et al (2019) Variability of black carbon mass concentrations, submicrometer particle number concentrations and size distributions: results of the German Ultrafine Aerosol Network ranging from city street to High Alpine locations. Atmos Environ 202:256-268. https://doi.org/10.1016/j. atmosenv.2018.12.029

61. Grange SK et al (2020) Evaluation of equivalent black carbon source apportionment using observations from Switzerland between 2008 and 2018. Atmos Meas Tech 13(4):1867-1885. https://doi.org/10.5194/ amt-13-1867-2020

62. https://www.eea.europa.eu/data-and-maps/dashboards/air-pollutantemissions-data-viewer-2. Accessed 16 June 2020.

63. Stein AF et al (2015) NOAA's HYSPLIT atmospheric transport and dispersion modeling system. Bull Am Meteor Soc 96(12):2059-2077. https://doi. org/10.1175/bams-d-14-00110.1

64. https://www.hysplit-pub.noaa.gov/hysplitpublic/limitations.html Accessed 1 Mar 2021

65. https://www.arl.noaa.gov/hysplit/hysplit-frequently-asked-questionsfaqs/faq-hg7/. Accessed 1 Mar 2021.

\section{Publisher's Note}

Springer Nature remains neutral with regard to jurisdictional claims in published maps and institutional affiliations.

\section{Submit your manuscript to a SpringerOpen ${ }^{\circ}$ journal and benefit from:}

- Convenient online submission

- Rigorous peer review

- Open access: articles freely available online

- High visibility within the field

Retaining the copyright to your article

Submit your next manuscript at springeropen.com 